\title{
Assessment and classification of subsidence after lateral interbody fusion using serial computed tomography
}

\author{
Gregory M. Malham, MBChB,, Rhiannon M. Parker, PhD, ${ }^{2}$ Carl M. Blecher, MBBS, DDU, ${ }^{3}$ and \\ Kevin A. Seex, MBChB ${ }^{4}$
}

${ }^{1}$ Neuroscience Institute, Epworth Hospital; ${ }^{2}$ Greg Malham Neurosurgeon; ${ }^{3}$ Radiology Department, Epworth Hospital, Melbourne, Victoria; and ${ }^{4}$ Neurosurgery Department, Macquarie University, Sydney, New South Wales, Australia

\begin{abstract}
OBJECT Intervertebral cage settling during bone remodeling after lumbar lateral interbody fusion (LIF) is a common occurrence during the normal healing process. Progression of this settling with endplate collapse is defined as subsidence. The purposes of this study were to 1) assess the rate of subsidence after minimally invasive (MIS) LIF by CT, 2) distinguish between early cage subsidence (ECS) and delayed cage subsidence (DCS), 3) propose a descriptive method for classifying the types of subsidence, and 4) discuss techniques for mitigating the risk of subsidence after MIS LIF.

METHODS A total of 128 consecutive patients (with 178 treated levels in total) underwent MIS LIF performed by a single surgeon. The subsidence was deemed to be ECS if it was evident on postoperative Day 2 CT images and was therefore the result of an intraoperative vertebral endplate injury and deemed DCS if it was detected on subsequent CT scans $(\geq 6$ months postoperatively). Endplate breaches were categorized as caudal (superior endplate) and/or cranial (inferior endplate), and as ipsilateral, contralateral, or bilateral with respect to the side of cage insertion. Subsidence seen in CT images (radiographic subsidence) was measured from the vertebral endplate to the caudal or cranial margin of the cage (in millimeters). Patient-reported outcome measures included visual analog scale, Oswestry Disability Index, and 36-Item Short Form Health Survey physical and mental component summary scores.
\end{abstract}

RESULTS Four patients had ECS in a total of 4 levels. The radiographic subsidence (DCS) rates were $10 \%$ (13 of 128 patients) and $8 \%$ (14 of 178 levels), with $3 \%$ of patients (4 of 128) exhibiting clinical subsidence. In the DCS levels, 3 types of subsidence were evident on coronal and sagittal CT scans: Type 1, caudal contralateral, in 14\% (2 of 14), Type 2, caudal bilateral with anterior cage tilt, in 64\% (9 of 14), and Type 3, both endplates bilaterally, in $21 \%$ (3 of 14). The mean subsidence in the DCS levels was $3.2 \mathrm{~mm}$. There was no significant difference between the numbers of patients in the subsidence (DCS) and no-subsidence groups who received clinical benefit from the surgical procedure, based on the minimum clinically important difference $(p>0.05)$. There was a significant difference between the fusion rates at 6 months ( $p=0.0195)$; however, by 12 months, the difference was not significant $(p=0.2049)$.

CONCLUSIONS The authors distinguished between ECS and DCS. Radiographic subsidence (DCS) was categorized using descriptors for the location and severity of the subsidence. Neither interbody fusion rates nor clinical outcomes were affected by radiographic subsidence. To protect patients from subsidence after MIS LIF, the surgeon needs to take care with the caudal endplate during cage insertion. If a caudal bilateral (Type 2) endplate breach is detected, supplemental posterior fixation to arrest progression and facilitate fusion is recommended.

http://thejns.org/doi/abs/10.3171/2015.1.SPINE14566

KEY WORDS CT; fusion; lumbar; minimally invasive; spine; subsidence

\footnotetext{
ABBREVIATIONS ALIF = anterior lumbar interbody fusion; BMI = body mass index; $\mathrm{DCS}=$ delayed cage subsidence; $\mathrm{ECS}=$ early cage subsidence; $\mathrm{LIF}=$ lateral interbody fusion; $\mathrm{MCID}=$ minimum clinically important difference; $\mathrm{MCS}$ = mental component summary; MIS = minimally invasive; ODI = Oswestry Disability Index; PCS = physical component summary; PLIF = posterior lumbar interbody fusion; SF-36 = 36-Item Short Form Health Survey; TLIF = transforaminal lumber interbody fusion; VAS = visual analog scale.

SUBMITTED June 4, 2014. ACCEPTED January 27, 2015.

INCLUDE WHEN CITING Published online July 24, 2015; DOI: 10.3171/2015.1.SPINE14566.

DISCLOSURE The authors report no conflict of interest concerning the materials or methods used in this study or the findings specified in this paper.
} 
$\mathrm{M}$ INIMALLY invasive lateral interbody fusion (MIS LIF) through a retroperitoneal transpsoas approach is a less invasive alternative for spinal fusion and provides several advantages over conventional anterior (anterior lumbar interbody fusion [ALIF]) and posterior (posterior [PLIF] or transforaminal lumber interbody fusion [TLIF]) approaches. Minimally invasive LIF permits the insertion of a large-footprint interbody cage that spans the lateral borders of the ring apophysis to maximize contact with the cortical bone, which aids in disc height restoration, correction of coronal and sagittal alignment, and indirect decompression. ${ }^{4,15,21}$ The lateral approach preserves the ligamentous structures and places them under tension, which leads to improved biomechanical stability of the spinal segment. ${ }^{1,4}$

The risks of performing MIS LIF are related primarily to injury of the lumbar plexus during the transpsoas approach, although cage migration and graft subsidence have also been reported. ${ }^{12,16,17}$

Biomechanical data indicate that there is greater stability of the spinal segment with pedicle screw fixation than with stand-alone treatment, ${ }^{1,4}$ potentially indicating a resistance to intervertebral cage subsidence. However, stand-alone MIS LIF prevents the morbidity associated with pedicle screw fixation and has been shown to be a successful method for achieving lumbar interbody fusion in appropriately selected patients..$^{13,17}$

Intervertebral cage settling during bone remodeling is a common occurrence in the normal healing process. Subsidence that can be seen on CT images (radiographic subsidence) represents the progression of this intervertebral cage settling with endplate collapse. Regardless of the approach used, subsidence can be a potential complication; it diminishes the goals of interbody fusion surgery, namely, disc or foraminal height restoration, indirect decompression, and segmental alignment. Thus, subsidence is of particular concern after ALIF and MIS LIF because these techniques rely on indirect decompression of the neural elements. Many factors contribute to intervertebral cage subsidence, including bone quality, cage morphology, the use of osteobiologics, the application of supplemental fixation, and iatrogenic endplate violation. Despite evidence of subsidence on postoperative imaging, the correlation of symptoms with subsidence is rare ${ }^{12}$ and is defined as clinical subsidence.

At least 3 grading systems for subsidence after MIS LIF have been proposed, ${ }^{12,16,24}$ with severity (percent collapse) as the primary consideration. The rate of subsidence after MIS LIF has been reported to be as high as $17 \% \%^{12,16}$ however, the inconsistencies in evaluating, defining, and reporting subsidence after this procedure make the significance of such findings unclear. The mechanisms and subsequent clinical effects of subsidence have not been categorized.

In this study, we aimed to 1) assess the rate of subsidence after MIS LIF according to CT scans, 2) distinguish between early cage subsidence (ECS) and delayed cage subsidence (DCS), 3) propose a descriptive method for classifying the types of subsidence, and 4) discuss techniques for mitigating the risk of subsidence after MIS LIF.

\section{Methods}

A prospective registry was analyzed retrospectively to find patients treated with the XLIF system (NuVasive, Inc.) by a single surgeon (G.M.M.) between February 2011 and October 2013.

Each patient underwent MIS LIF between L1-2 and L4-5 with or without supplemental posterior instrumentation. The indication for supplemental fixation followed a treatment algorithm developed by us. ${ }^{13}$ Information required for the algorithm included bone density, degree of facet arthropathy, the number of proposed levels, coronal or sagittal imbalance, spondylolisthesis, instability, pars defects, and the presence of an adjacent fusion. Bone mineral density (dual-energy x-ray absorptiometry) scanning was performed for each patient older than 70 years and for any patient with risk factors for low bone mineral density. Every patient with posterior instrumentation received percutaneous pedicle screws (NuVasive Inc.).

\section{Surgical Technique}

The MIS LIF procedure has been described previously. ${ }^{13,22}$ Each patient was fitted with a $10^{\circ}$ lordotic intervertebral polyetheretherketone (PEEK) cage (CoRoent, NuVasive, Inc.). The cages were 50,55 , or $60 \mathrm{~mm}$ in length (lateral dimension), 18 or $22 \mathrm{~mm}$ in width (anterior to posterior), and 8,10 , or $12 \mathrm{~mm}$ in height (inferior to superior). The cage was filled with either of the following: 1) AttraX (NuVasive, Inc.), which is an osteoinductive synthetic bone putty composed of $95 \% \beta-\mathrm{TCP}$ (tricalcium phosphate) and $5 \%$ hydroxyapatite, or 2) a combination of recombinant human bone morphogenetic protein-2 (Infuse, Medtronic, Inc.) and Mastergraft $\beta$-TCP granules (Medtronic, Inc.). Infuse had a fixed concentration of $1.5 \mathrm{mg} / \mathrm{ml}$, and the dose used per level was volume dependent (i.e., the internal volume of the cage equaled the Infuse volume in milliliters). ${ }^{2,3}$ The use of Infuse was off-label. We used a small Infuse kit per Boden et $\mathrm{al}^{3}{ }^{3}$ ( $2.8 \mathrm{ml}$, providing a $4.2-\mathrm{mg}$ dose). No Infuse was placed outside the cage.

\section{Clinical Assessment}

Baseline patient information included demographics, medical comorbidities, and the primary indication for surgery. Treatment information included the levels treated, the osteobiologics used, and the requirement for supplemental posterior instrumentation. Each patient was assessed preoperatively and at each routine postoperative clinical follow-up (6 weeks and 3, 6, and 12 months); patients whose vertebrae were not fused by 12 months were followed up at 6-month intervals until confirmation of solid interbody fusion. Patient-reported outcomes included back and leg pain (visual analog scale [VAS]), disability (Oswestry Disability Index [ODI]), and quality of life (36Item Short Form Health Survey [SF-36] physical component summary [PCS] and mental component summary [MCS] scores).

\section{Radiographic Assessment}

CT scans were acquired using a high-definition CT machine (Somatom Definition Flash, Siemens AG) and evaluated by an independent radiologist (C.M.B.) from within 
the treating institution. The CT scans were obtained 2 days after surgery to assess cage position and instrumentation and to identify possible endplate violation. Additional CT scans were obtained at routine 6-, 12-, 18-, and 24-month follow-ups to assess fusion status and subsidence. Fusion was defined as the presence of bridging interbody trabecular bone as seen in coronal and sagittal views. ${ }^{28}$ Because of concerns regarding cancer risk from radiation exposure, no scans were acquired after solid interbody fusion was confirmed.

Radiographic subsidence was defined as any compromise of either endplate. Each patient with evidence of subsidence underwent evaluation and quantification of morphological changes to the endplates and vertebra. Subsidence was deemed ECS if it was evident on postoperative Day 2 CT images and was therefore the result of an intraoperative vertebral endplate violation. If the postoperative Day $2 \mathrm{CT}$ images showed symmetrically inserted cages and no evidence of endplate violation but subsidence was detected on subsequent CT scans ( $\geq 6$ months after surgery), it was deemed DCS.

Endplate breaches were categorized as caudal (superior endplate) and/or cranial (inferior endplate) and as ipsilateral, contralateral, or bilateral with respect to the side of cage insertion. All incidences of subsidence were described according to these categories, which enabled a subsidence-typing system to be developed. Radiographic subsidence was measured from the vertebral endplate to the caudal or cranial margin of the cage (in millimeters) (Fig. 1). Measurements were obtained digitally by using InteleViewer software (Intelerad Medical Systems, Inc.).

Clinical subsidence was defined as radiographic subsidence with recurrent pain, recurrent neurological symptoms, or a significant decline in clinical outcome measures related to loss of indirect decompression. ${ }^{12}$

\section{Statistical Analysis}

Statistical analysis was carried out using IBM SPSS Statistics version 21.0 (IBM Corp.) and included paired ttests, independent-samples t-tests, and Fisher's exact tests; a measured $p$ value of $<0.05$ was considered statistically significant.

The minimum clinically important difference (MCID) ${ }^{6}$ was used to compare the clinical outcomes between patients in the subsidence group and those in the no-subsidence group by identifying the number of patients in each group who received clinical benefit from the surgical procedure. To be identified as receiving clinical benefit, the patient had to meet the following defined thresholds for the MCID: a 1.2-point improvement in back pain, a 1.6-point improvement in leg pain, a 12.8-point improvement in ODI, and a 4.9-point improvement in PCS score. ${ }^{6}$

\section{Results}

At total of 128 consecutive patients treated with MIS LIF were included in the analysis, and a total of 178 levels were treated. A summary of the patient demographic and treatment information is provided in Table 1 . The mean follow-up duration was 25.1 months (range 12-36 months).

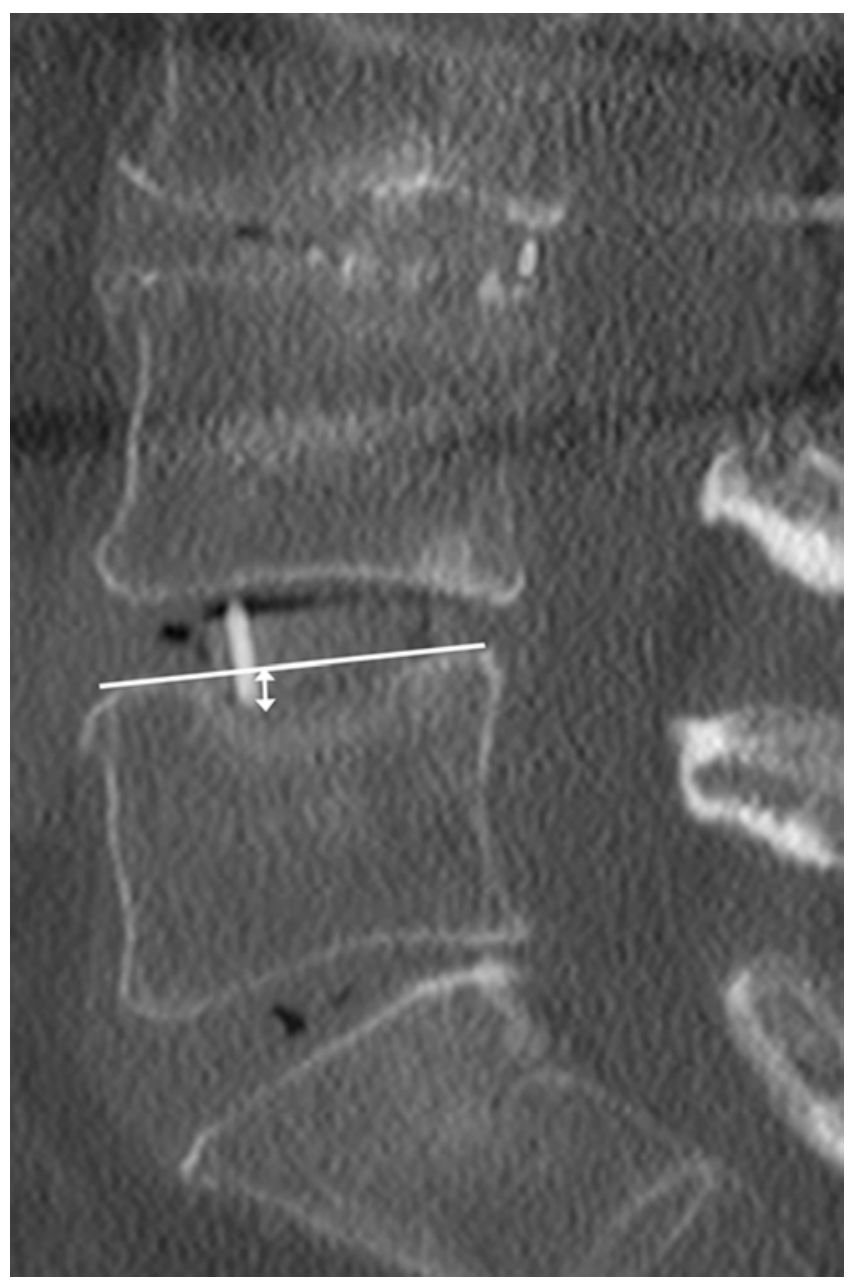

FIG. 1. Measurement of subsidence.

\section{Radiological Results}

Four (3\%) patients had ECS at a total of 4 levels, which provides an ECS incidence of 2\% (4 of 178 levels). The first 2 patients were women aged 60 and 75 years who each underwent L3-4 and L4-5 MIS LIF; during impaction of the L3-4 cage into a narrow disc space, the caudal L-4 endplate was breached. Bilateral pedicle screw fixation was added in both cases to maintain cage position. The third patient was a man aged 53 years who had undergone multiple revision lumbar fusions with bilateral pedicle screw fixation in situ and required interbody support at L2-3 and L3-4. The caudal L-3 endplate was breached on impaction of the cage into the L2-3 disc space. The fourth patient was an 86-year-old woman who suffered an L-5 anterior caudal endplate injury on impaction of the cage into the L4-5 disc space. Bilateral pedicle screw fixation was added to maintain cage position.

Because each case of ECS was caused by intraoperative vertebral endplate injury rather than progressive settling of the cage into the adjacent vertebra, these 4 patients were removed from subsequent analyses of the patients with DCS and those without subsidence.

Thirteen (10\%) patients had DCS at a total of 14 levels, which provides a DCS incidence of $8 \%$ (14 of 178 levels). The mean age of the patients with DCS was 64.7 years 
(range 48-81 years), and $7(54 \%)$ of them were female. Seven patients $(54 \%)$ had a stand-alone fusion, and $6(46 \%)$ underwent instrumentation. The cage widths used were $18 \mathrm{~mm}$ in $9(64 \%)$ of the subsided levels and $22 \mathrm{~mm}$ in 5 (36\%). Infuse was used in $13(93 \%)$ of the subsided levels, and AttraX was used in $1(7 \%)$. Ten cases (71\%) of DCS occurred at L4-5 and the remaining $4(29 \%)$ at L3-4. A comparison of factors known to contribute to subsidence,

TABLE 1. Patient demographic and treatment information*

\begin{tabular}{|c|c|}
\hline Characteristic & Patient Data $(n=128)$ \\
\hline Age (yrs) & $63.0 \pm 11.0(27-86)$ \\
\hline Female & $87(68)$ \\
\hline $\mathrm{BMI}\left(\mathrm{kg} / \mathrm{m}^{2}\right)$ & $27.3 \pm 5.1(17.6-40.8)$ \\
\hline Bone density (T-score)† & $-1.4 \pm 0.9(-4.3$ to -0.2$)$ \\
\hline \multicolumn{2}{|l|}{ Comorbidities } \\
\hline Diabetes & $10(8)$ \\
\hline Smoker & $15(12)$ \\
\hline Previous lumbar surgery & $48(38)$ \\
\hline Artificial disc & $1(2)$ \\
\hline Fusion & $15(31)$ \\
\hline Laminectomy & $24(50)$ \\
\hline Microdiscectomy & $8(17)$ \\
\hline \multicolumn{2}{|l|}{ Primary dagnosis } \\
\hline Adjacent-segment disease & $6(5)$ \\
\hline Degenerative disc disease & $33(26)$ \\
\hline Discogenic pain & $10(8)$ \\
\hline Dislocated artificial disc & $1(1)$ \\
\hline Herniated nucleus pulposus & $14(11)$ \\
\hline Pseudarthrosis & $1(1)$ \\
\hline Scoliosis & $19(15)$ \\
\hline Spondylolisthesis & $32(25)$ \\
\hline Stenosis & $12(9)$ \\
\hline Levels treated (per patient) & $178 \pm 1.4(1-3)$ \\
\hline $\mathrm{L} 1-2$ & $3(2)$ \\
\hline L2-3 & $25(14)$ \\
\hline L3-4 & $65(37)$ \\
\hline L4-5 & $85(48)$ \\
\hline \multicolumn{2}{|l|}{ Levels per operation } \\
\hline 1 level & $85(66)$ \\
\hline 2 levels & $36(28)$ \\
\hline 3 levels & $7(5)$ \\
\hline \multicolumn{2}{|l|}{ Cage width } \\
\hline $18 \mathrm{~mm}$ & $81(46)$ \\
\hline $22 \mathrm{~mm}$ & $97(54)$ \\
\hline \multicolumn{2}{|l|}{ Biologics used } \\
\hline Infuse & $105(82)$ \\
\hline AttraX & $23(18)$ \\
\hline \multicolumn{2}{|l|}{ Fixation type } \\
\hline Stand-alone & $56(44)$ \\
\hline Transpedicular bilateral fixation & $72(56)$ \\
\hline
\end{tabular}

including body mass index (BMI), bone density, smoking, biologics used, and posterior instrumentation, is provided in Table 2. There were no statistically significant differences between any of these factors $(p>0.05)$ except for smoking, which was higher in the subsidence group $(\mathrm{p}=0.05)$.

In the evaluation of the DCS levels (14 levels), the 3 following types of subsidence were evident on coronal and sagittal CT images (Fig. 2): Type 1, caudal contralateral, in 2 cases (14\%); Type 2, caudal bilateral with anterior cage tilt, in 9 (64\%); and Type 3, both caudal and cranial endplates bilaterally, in $3(21 \%)$. There were no cases of cranial endplate subsidence in the absence of caudal subsidence. Figures 3-5 show CT examples of the 3 types of subsidence found in this series. The mean subsidence in the DCS levels was $3.2 \mathrm{~mm}$ (range 1.6-6.0 mm).

Interbody fusion rates for the subsidence group (DCS) progressed from $0 \%$ at 6 months to $54 \%$ at 12 months, to $73 \%$ at 18 months, and to $90 \%$ at 24 months. For the no-subsidence group, interbody fusion rates progressed from $30 \%$ at 6 months to $72 \%$ at 12 months, to $88 \%$ at 18 months, and to $93 \%$ at 24 months (Table 3). The only difference in fusion rates between the subsidence and nosubsidence groups that was statistically significant was that at 6 months $(\mathrm{p}=0.0195)$.

There were 8 patients ( 9 levels in total) with Type 2 subsidence; of the 4 patients who underwent pedicle screw fixation, all levels were fused by 18 months (range 12-18 months). However, of the 4 patients who did not receive pedicle screws, none of the levels were fused by 18 months after surgery. Two patients underwent pedicle screw fixation and at the 6-month follow-up showed evidence of early interbody fusion on coronal and sagittal CT images. The remaining 2 patients chose not to undergo screw fixation because they had already had excellent clinical outcomes.

\section{Clinical Results}

For the subsidence group (DCS), the mean back and leg pain VAS scores improved from 6.1 to 1.8 and 6.4 to 1.3 ,

TABLE 2. Comparison of subsidence risk factors between patients with DCS and those with no subsidence*

\begin{tabular}{|c|c|c|c|}
\hline Characteristic & $\begin{array}{l}\text { Subsidence } \\
\text { Group } \\
(n=13)\end{array}$ & $\begin{array}{l}\text { No-Subsidence } \\
\text { Group }(n=111)\end{array}$ & $\mathrm{p}$ Value \\
\hline \multicolumn{4}{|l|}{ Comorbidities } \\
\hline BMI & 26.5 & 27.4 & 0.5855 \\
\hline Bone density (T-score)† & -0.7 & -1.5 & 0.7789 \\
\hline Smoker & $4(31)$ & $11(10)$ & 0.0519 \\
\hline \multicolumn{4}{|l|}{ Biologics used } \\
\hline Infuse & $12(92)$ & $90(81)$ & 0.4609 \\
\hline AttraX & $1(8)$ & $21(19)$ & \\
\hline \multicolumn{4}{|l|}{ Fixation type } \\
\hline Stand-alone & $7(54)$ & $48(43)$ & 0.5600 \\
\hline $\begin{array}{l}\text { Transpedicular bilateral } \\
\text { fixation }\end{array}$ & $6(46)$ & $63(57)$ & \\
\hline
\end{tabular}



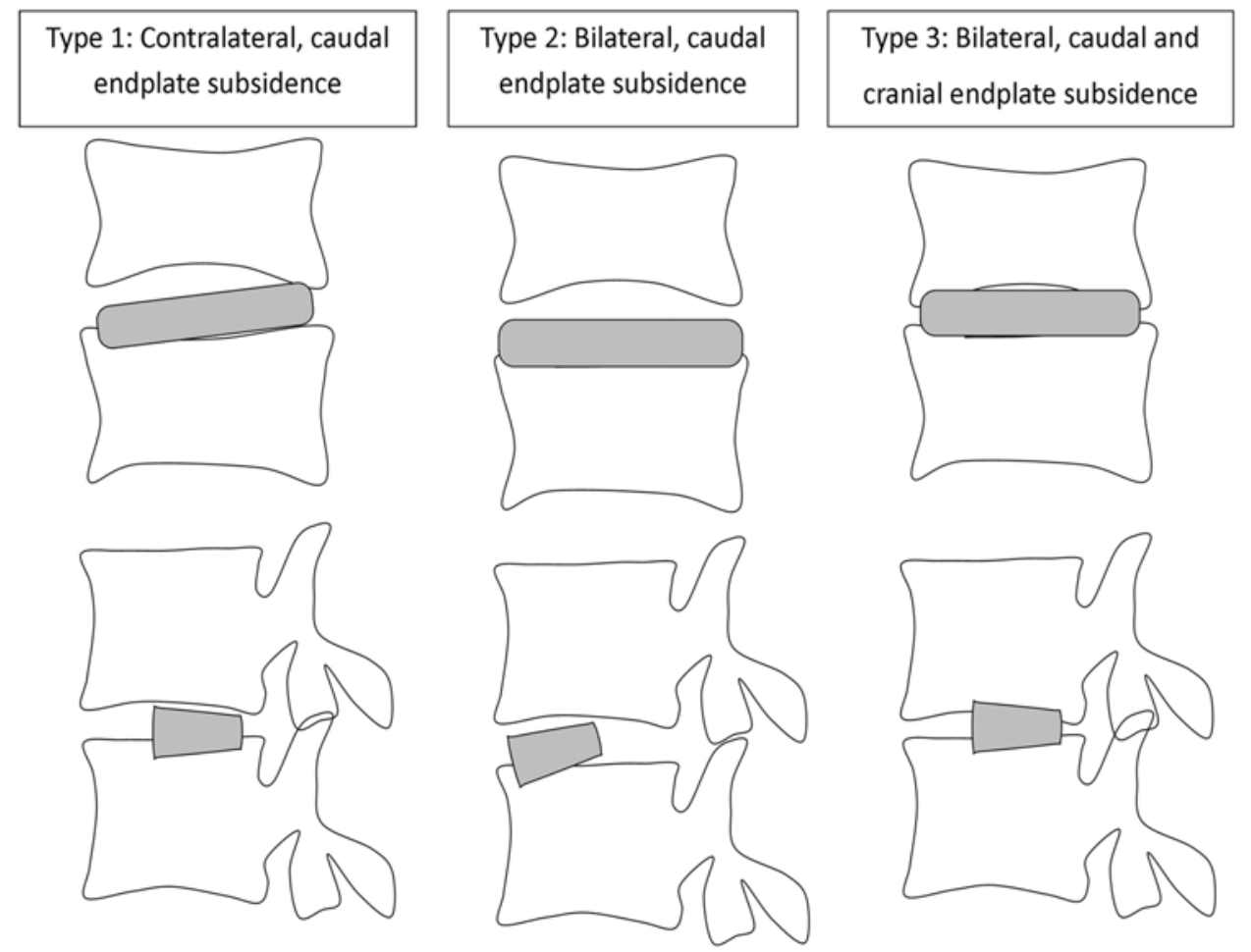

FIG. 2. The 3 types of subsidence described in this study.

representing improvements of $71 \%$ and $69 \%$, respectively. The mean ODI score improved from 52.1 to 23.2 (55\%), and the PCS and MCS scores improved from 29.0 to 44.5 $(53 \%)$ and 47.9 to $56.1(17 \%)$, respectively. Four of the 13 patients had clinical (symptomatic) subsidence, which provided a clinical subsidence rate of 3\% (4 of 128). Preoperative and final follow-up (range 12-36 months) mean ODI scores for the patients with radiographic subsidence and for those with clinical subsidence were 50.6 to 21.5 (57.5\% improvement) and 56.0 to 27.7 (50.5\% improvement), respectively $(\mathrm{p}=0.9240)$. The VAS and SF-36 results were also similar, with no significant difference in improvement between the patients with radiographic subsidence and those with clinical subsidence (all $\mathrm{p}>0.05$ ).

For the patients with no subsidence, the mean back and leg pain VAS scores improved from 6.7 to 3.5 and 6.3 to 2.9 , representing improvements of $46 \%$ and $44 \%$, respectively. The mean ODI improved from 52.4 to 32.8 (37\%), with PCS and MCS scores improving 34\% (29.3 to 39.2 ) and $7 \%$ (45.1 to 48.1), respectively. All clinical results for the subsidence and no-subsidence groups were statistically significantly over those at baseline $(p<0.05)$. A summary of the clinical results is provided in Table 4.

The $\mathrm{MCID}^{7}$ criteria were used to compare the number of patients in the subsidence and no-subsidence groups who met the threshold for clinical benefit from the surgical procedure. There were no statistically significant differences $(p>0.05)$ between the subsidence and no-subsidence groups in the number of patients who met the MCID criteria (Table 4).

\section{Discussion}

Subsidence is a progressive impaction or settling of the cage into the adjacent vertebra. Subsidence can be related to many factors including surgical technique, cage morphology, the use of osteobiologics, and bone quality.

The rate of interbody cage subsidence is reduced when the cage spans the cortical bone of the apophyseal ring and the footprint is greater than $30 \%$ of the endplate. ${ }^{5.9}$ Posterior approaches for interbody fusion (TLIF and PLIF) use 1 or 2 small intervertebral cages, typically covering between $13 \%$ and $25 \%$ of the endplate, respectively, and rarely covering the stronger posterior and lateral borders of the apophyseal ring. ${ }^{919}$ Although interbody cage subsidence is common with posterior approaches (up to $22 \%{ }^{25,26}$ ), it is less clinically and radiographically relevant, because direct decompressions are used and alignment is corrected by compressive posterior instrumentation.

Anterior interbody approaches (ALIF and MIS LIF) allow placement of large intervertebral cages that are the primary mechanism for the restoration of disc height and spinal alignment, resulting in indirect decompression. Hence, the effects of subsidence have become a greater concern than those resulting from posterior approaches. ${ }^{7,17,21,23}$

We distinguished between ECS and DCS. ECS was evident on postoperative Day 2 CT images and, hence, was the result of an intraoperative endplate injury. Subsidence was deemed DCS if the postoperative Day 2 CT images showed symmetrically inserted cages and no evidence of endplate injury but if subsidence was detected on subsequent scans ( $\geq 6$ months after surgery).

All 4 of our ECS cases were of direct intraoperative impaction of the cage into the caudal endplate bilaterally. The caudal endplate is $40 \%$ weaker than the cranial endplate $^{9}$ and thus is at higher risk of injury and subsidence. ${ }^{12}$ 

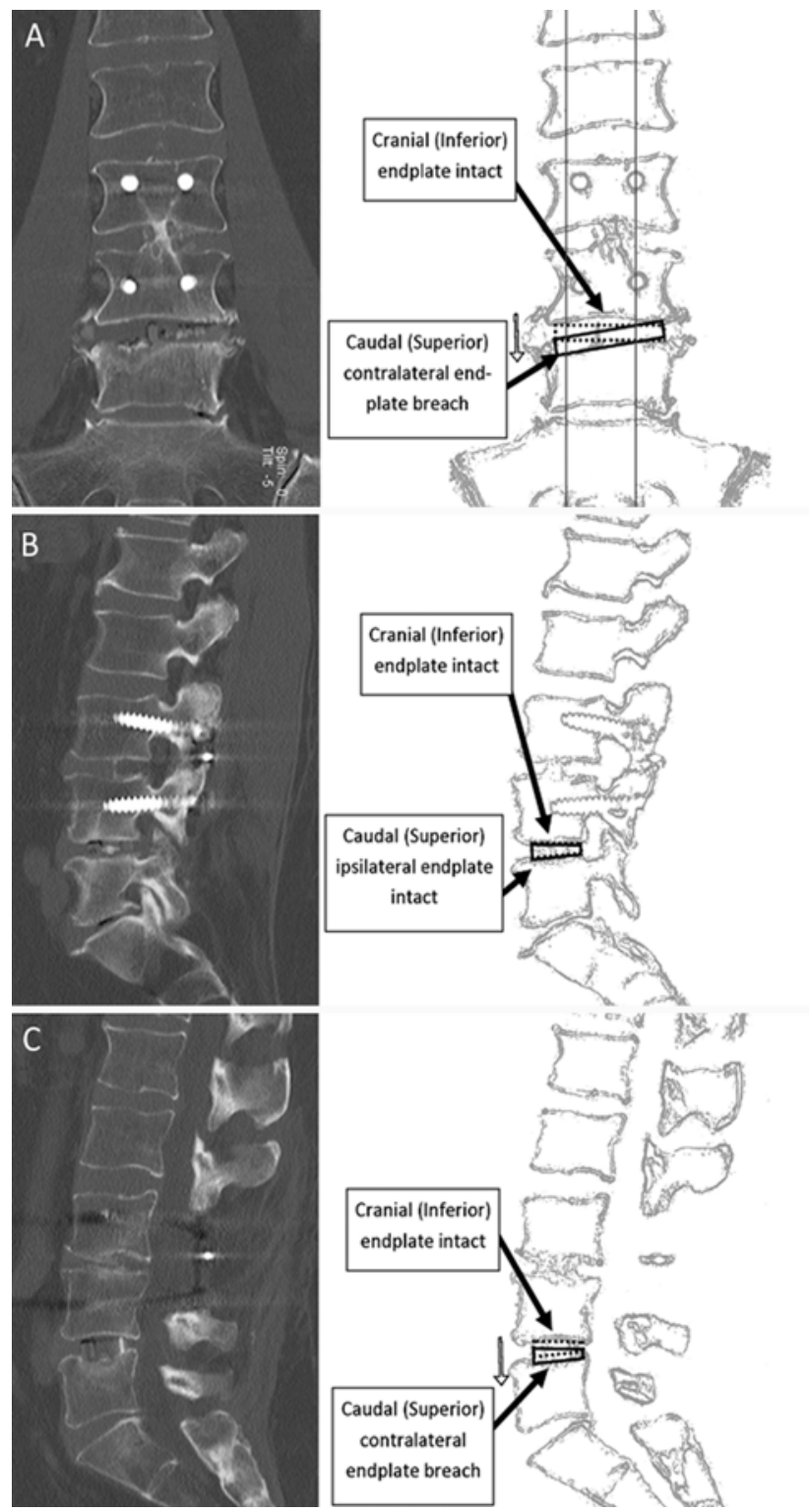

FIG. 3. Type 1: caudal contralateral subsidence. A: Coronal CT image. B: Sagittal CT image, ipsilateral. C: Sagittal CT image, contralateral.

In addition, the anterior tilting of the cage is consistent with the anterior endplate cortical rim being weaker ${ }^{9}$ and of thinner depth than both the middle and posterior rims. ${ }^{10}$ The stronger cranial endplate usually remains intact. Cage height in our series was restricted to $8-12 \mathrm{~mm}$ in a conscious effort to avoid possible endplate overdistraction and violation.

In our series, $10 \%$ of the patients (13 of 128) exhibited radiographic evidence of subsidence (DCS) after MIS LIF, with an incidence of 8\% (14 of 178 levels). Clinical (symptomatic) subsidence was exhibited in $3 \%$ of the patients (4 of 128). Le et al. ${ }^{12}$ reported a similar radiographic subsidence rate of $14.3 \%$ (20 of 140) of patients in $8.8 \%$ (21 of 238 ) of levels, with clinical subsidence in $2.1 \%$. Subsidence after stand-alone MIS LIF was examined by Marchi et al. in 2 separate studies; they found subsidence rates of $17 \%$
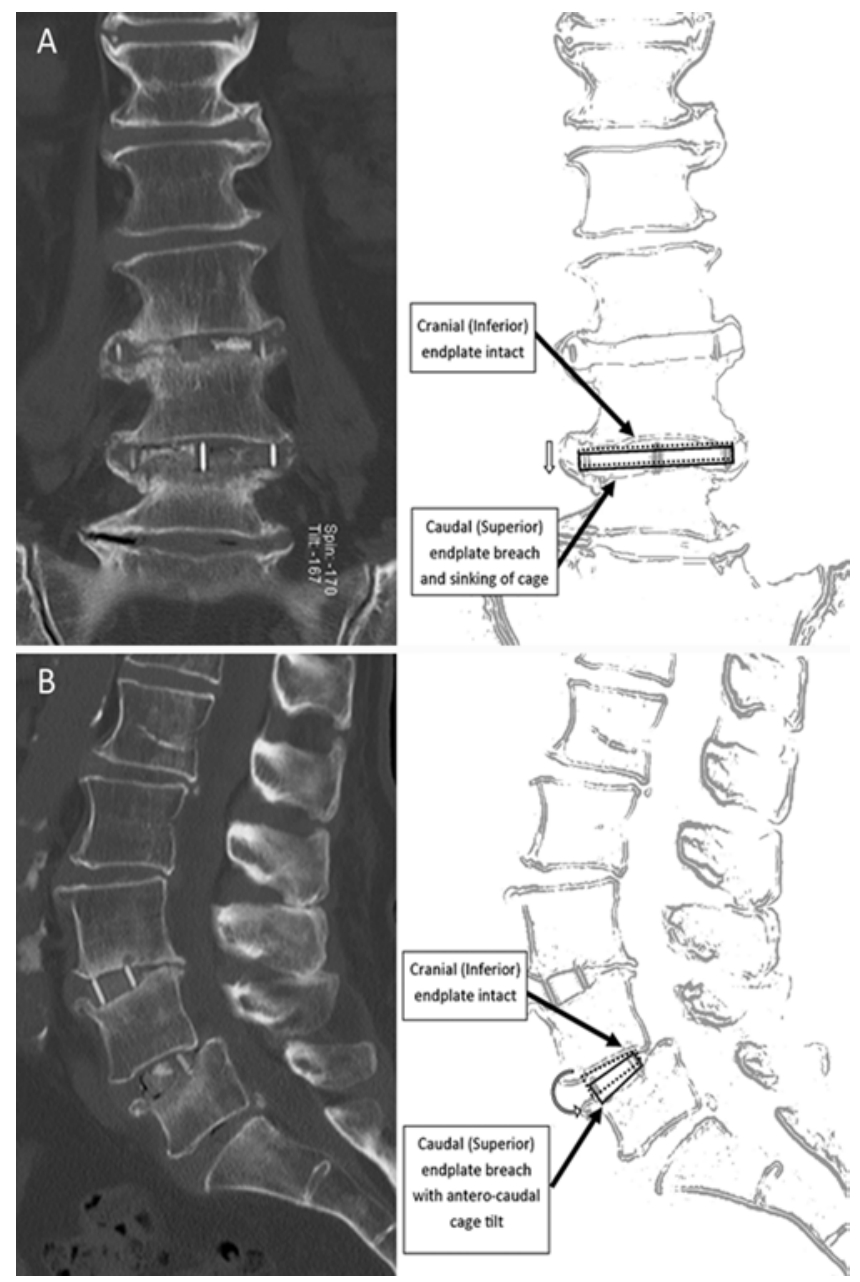

FIG. 4. Type 2: caudal bilateral subsidence. A: Coronal CT image. B: Sagittal CT image.

(in 9 of 52 patients) $)^{17}$ and $14.3 \%$ (at 4 of 28 levels). ${ }^{18}$ The depth of subsidence in our series ranged from 1.6 to 6.0 $\mathrm{mm}$, similar to the 2- to 9-mm range reported by Le et al. ${ }^{12}$

DCS occurred between 2 days and 6 months after surgery, which is consistent with the results of other studies that noted subsidence occurring in the early postoperative period between 6 weeks and 3 months. . $^{16,18}$ We observed a rate of DCS associated with the use of $18-\mathrm{mm}$ cages that was higher than that with 22-mm cages; the overall incidences were $11 \%$ (9 of 81 ) and 5\% (5 of 97), respectively. Despite not being statistically significant $(\mathrm{p}=0.1686)$, this finding is consistent with that of Le at al., ${ }^{12}$ who reported 18- and 22-mm cages resulting in subsidence rates of $14.1 \%$ and $1.9 \%$, respectively ( $<<0.0001)$. The larger surface area of the 22-mm cages covers more of the stronger peripheral endplates and leads to more efficient transfer of force to the endplate that that of the 18 -mm cages. Le et al. ${ }^{12}$ found that implant length had no effect on subsidence rates as long as it covered the periphery of the vertebral bodies.

The L4-5 level had the highest rate of subsidence at $12 \%$ (10 of 85 levels). Although this result, again, was not significant ( $p=0.2731$ ), it is similar to that reported in an earlier study by Marchi et al. ${ }^{17}$ who noted the highest rate 

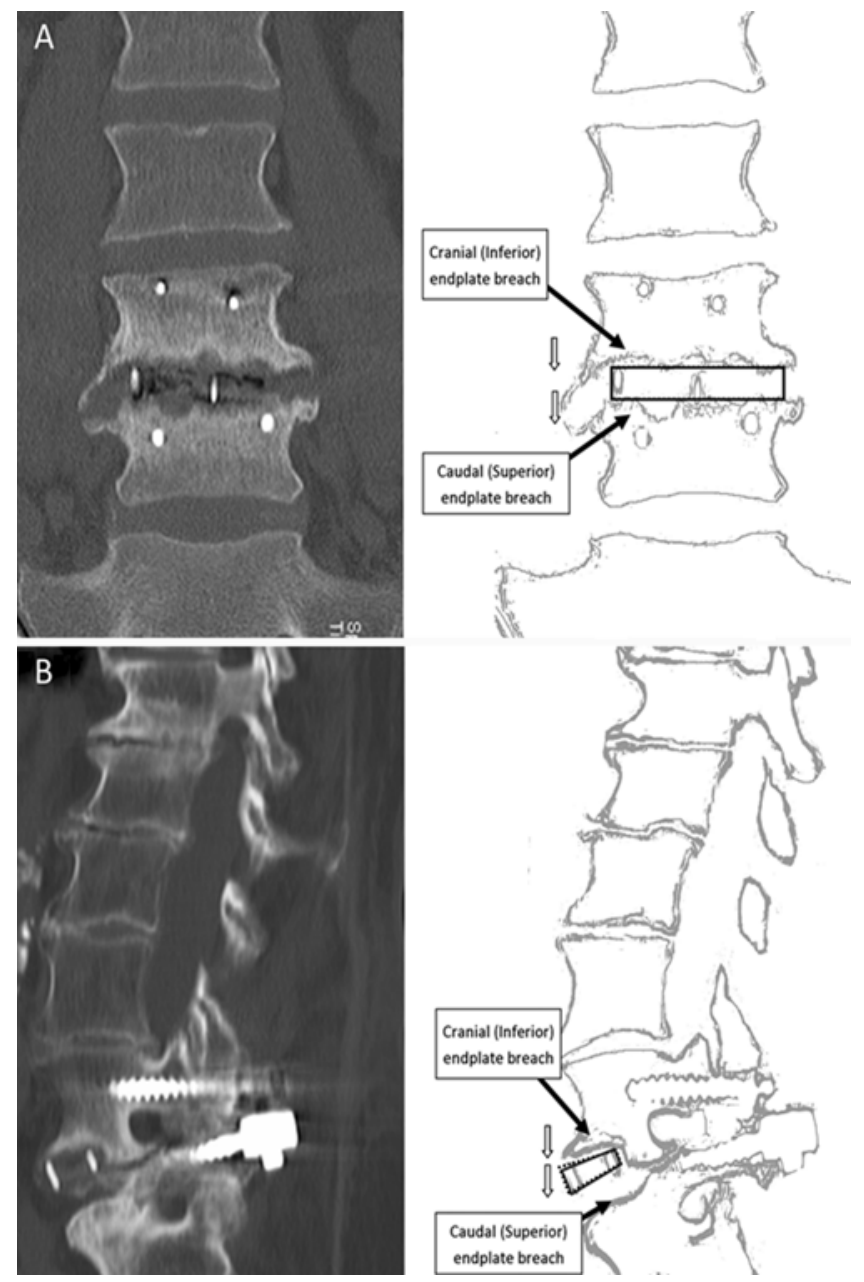

FIG. 5. Type 3: caudal and cranial bilateral subsidence. A: Coronal CT image. B: Sagittal CT image.

of subsidence at the L4-5 level, with $44.2 \%$ of Grade $0 / \mathrm{I}$ and $88.9 \%$ of Grade II/III subsidence occurring at L4-5 $(p=0.038)$. Although lumbar endplate strength increases from L1-2 to L4-5, ${ }^{27} \mathrm{~L} 4-5$ is technically the most challenging level because the lumbar plexus can dictate the anterior cage position and the height of the iliac crest can prevent parallel entry, often concurrently.

We found no statistically significant difference between any of the factors known to contribute to subsidence, including BMI, bone density, and posterior instrumentation (p > 0.05) (Table 2). However, there was a significantly higher number of smokers in the subsidence group $(\mathrm{p}=$ $0.05)$ than the no-subsidence group. Smoking is a potent cause of subsidence and nonunion in lumbar fusion surgery, because nicotine causes tissue hypoxia and is toxic to osteoblasts. ${ }^{11}$ Smoking has been shown to adversely affect lumbar fusion rates in patients treated with Infuse. , $^{8,14}$

Alternatively, DCS may have a different set of causative factors, such as Infuse-related osteolysis. ${ }^{20}$ This is of particular concern in the first 4-6 postoperative weeks during the initial recombinant human bone morphogenetic protein 2-induced osteoclastic inflammatory response and resorption phase before osteoblastic bone formation and consolidation, which can result in cage subsidence and
TABLE 3. Interbody fusion rates for patients with DCS and those with no subsidence

\begin{tabular}{|c|c|c|c|}
\hline \multirow[b]{2}{*}{$\begin{array}{c}\text { Follow-Up } \\
\text { (mos) }\end{array}$} & \multicolumn{2}{|c|}{ \% Solid Fusion (no. fused/total no.) } & \multirow[b]{2}{*}{$\mathrm{p}$ Value } \\
\hline & $\begin{array}{l}\text { Subsidence Group } \\
\qquad(n=13)\end{array}$ & $\begin{array}{l}\text { No-Subsidence Group } \\
\qquad(\mathrm{n}=111)\end{array}$ & \\
\hline 6 & $0(0 / 13)$ & $30(33 / 111)$ & 0.0195 \\
\hline 12 & $54(7 / 13)$ & $72(80 / 111)$ & 0.2049 \\
\hline 18 & $73(8 / 11)$ & $88(85 / 97)$ & 0.1792 \\
\hline 24 & $90(9 / 10)$ & $93(68 / 73)$ & 0.5490 \\
\hline
\end{tabular}

screw loosening. ${ }^{25}$ However, there was no significant difference between the subsidence rates of our patients who received the osteobiologics, Infuse or AttraX $(p=0.4609)$. In addition, the 4.2-mg dose of Infuse used in our study was double the 2.1-mg dose used by Le et al. ${ }^{12}$ however, the rates of subsidence within our study were similar (10\% vs $14.3 \%$, respectively).

We found that neither interbody fusion rates nor clinical outcomes were affected by radiographic subsidence. Despite the significant difference in fusion rates between the subsidence and no-subsidence groups at 6 months $(0 \%$ and $30 \%$, respectively; $p=0.0195$ ), by 18 months the fusion rates for both groups were similar $(73 \%$ and $88 \%, \mathrm{p}=$ 0.1792 ). These fusion rates are comparable to the 12- and 24-month fusion rates of $67 \%$ and $86 \%$, respectively, reported by March et al. ${ }^{17}$ and confirmed with CT images.

In our series there was no significant difference between the number of patients in the subsidence group and those in the no-subsidence groups who received clinical benefit from the procedure based on the MCID criteria ${ }^{6}(p>0.05)$. Similar results were also reported by Marchi et al.:16 however, they did find a significant difference 6 weeks after surgery, suggesting that clinically relevant subsidence may result from transient pain caused by bony changes, which subsequently stabilizes over time.

Three classification systems for subsidence have been described in the literature. Le et al. ${ }^{12}$ simply identified whether subsidence, defined as any compromise of the endplate, was present. Sharma et al..$^{24}$ combined location and severity to described 4 classes of subsidence. Marchi et al. ${ }^{17}$ referenced the amount of subsidence as a percentage of the cage height by using an increasing 4-point severity scale. However, Grade 0 was defined as including an intact endplate through to subsidence of $24 \%$. We suggest measuring subsidence in millimeters and adding a description of cage orientation to make a clear distinction between ECS and DCS.

With our data, 3 types of subsidence were identified. Type 1 was cage subsidence into the contralateral caudal endplate without anterior cage tilt, which occurred in $14 \%$ of our DCS levels. Type 2 was the most common (64\%) and involved bilateral cage subsidence into the anterior aspect of the caudal endplate, producing an anterior tilt of the cage. Type 3 was cage subsidence into both the caudal and cranial endplates bilaterally without cage tilt (21\%). These types are consistent with those of the 20 cases of subsidence reported in the study by Le et al., ${ }^{12}$ in which 14 patients $(70 \%)$ had subsidence involving the caudal endplate and only 6 involved the cranial endplate. Of those 6 
TABLE 4. Outcome data for patients with DCS and those with no subsidence

\begin{tabular}{|c|c|c|c|c|c|}
\hline \multirow[b]{2}{*}{ Outcome } & \multicolumn{2}{|c|}{ Subsidence Group $(n=13)^{*}$} & \multicolumn{2}{|c|}{ No-Subsidence Group $(n=111)^{*}$} & \multirow[b]{2}{*}{ Significance $(p) \ddagger$} \\
\hline & Preoperative & Last Follow-Up† & Preoperative & Last Follow-Up† & \\
\hline VAS score (back) & $6.1 \pm 2.6$ & $1.8 \pm 1.5$ & $6.7 \pm 1.9$ & $3.5 \pm 2.6$ & 0.7221 \\
\hline VAS score (leg) & $6.4 \pm 1.7$ & $1.3 \pm 2.1$ & $6.3 \pm 2.3$ & $2.9 \pm 2.7$ & 0.4812 \\
\hline ODI score & $52.1 \pm 13.6$ & $23.2 \pm 13.8$ & $52.4 \pm 13.6$ & $32.8 \pm 20.2$ & 0.0998 \\
\hline SF-36 PCS score & $29.0 \pm 6.4$ & $44.5 \pm 9.3$ & $29.3 \pm 7.7$ & $39.2 \pm 9.9$ & 0.1682 \\
\hline SF-36 MCS score & $47.9 \pm 10.9$ & $56.1 \pm 5.1$ & $45.1 \pm 11.3$ & $48.1 \pm 12.6$ & NA§ \\
\hline \multicolumn{6}{|c|}{$\begin{array}{l}\text { NA = not applicable. } \\
\text { * Values are presented as the mean } \pm \text { SD. } \\
\dagger \text { Last follow-up refers to the most recent outcome data for the patient (range 12-36 months). } \\
\ddagger \text { Comparison based on of the number of patients who met the defined thresholds for the MCID (Fisher's exact test). } \\
\S \text { The MCS does not have an MCID. }\end{array}$} \\
\hline
\end{tabular}

cranial endplate injuries, 4 involved both the caudal and cranial endplates. The isolated cranial endplate injuries ( 2 of 20 cases) were thought to be due to an aggressive surgical technique (J. S. Uribe, personal communication, 2013). Marchi et al..$^{16}$ also reported similar results; subsidence occurred at the caudal endplate in $68 \%$ of the cases $(\mathrm{p}=0.024)$, with both the anterior and posterior borders of the cages subsiding together rather than rotating into the endplate $(\mathrm{p}=0.009)$.

From a pragmatic point of view, distinction between the different subsidence types may help predict their natural history and give surgeons more confidence to reassure and observe rather than to use supplemental fixation or other interventions such as vertebroplasty. Our limited experience suggests that caudal contralateral subsidence and combined caudal/cranial bilateral subsidence (Types 1 and 3 , respectively) are benign injuries that fuse by 18 months. Caudal bilateral subsidence with anterior tilt (Type 2) requires supplemental fixation to arrest progression and facilitate fusion.

To minimize the rates of ECS and DCS, techniques to protect the integrity of the weaker ${ }^{9}$ and thinner ${ }^{10}$ caudal endplate should be used. Particular care must be taken when advancing the Cobb elevator, using manual force rather than a mallet and constantly referencing the anteroposterior image. In addition, aggressive endplate preparation with curettes and rasps should be avoided. Protective slides on the caudal endplate are recommended during disc space distraction and insertion of trials and cages. If an endplate breach is recognized intraoperatively, then Infuse should not be used and an alternative graft material should be chosen. Supplemental posterior fixation with bilateral pedicle screws is also recommended to provide the most biomechanically supportive long-term construct. ${ }^{4}$

The strengths of this study include the quality of follow-up with CT scans, rather than radiographs, interpreted by an independent radiologist. There was also a consistent surgical technique used by a single spine surgeon. The major limitation of this study is the low number of subsidence cases, which leaves the study underpowered to make conclusions on subgroup analyses of causal relationships. However, the results presented are similar to those of other studies $^{12,16-18}$; hence, we feel that the technical considerations and descriptive system provided in this study may prove useful in future studies.

\section{Conclusions}

In our series, the radiographic subsidence rate after MIS LIF, as assessed by using CT images, was $10 \%$ of patients and $8 \%$ of levels, with $3 \%$ exhibiting clinical subsidence. We distinguished between ECS and DCS; ECS was detected on postoperative Day 2 CT images and was therefore caused by intraoperative endplate injury, and for DCS, no evidence of subsidence was found in the Day 2 CT images but was detected in subsequent images $(\geq 6$ months after surgery). Radiographic subsidence was categorized using descriptors for the location and severity of subsidence. The most common type of subsidence was Type 2, which involved bilateral cage subsidence into the anterior aspect of the caudal endplate, producing an anterior tilt of the cage. Neither interbody fusion rates nor clinical outcomes were affected by radiographic subsidence. To protect patients from subsidence after MIS LIF, the surgeon needs to take care with the caudal endplate during cage insertion. If a Type 2 subsidence is detected, supplemental posterior fixation is recommended to arrest progression and facilitate fusion.

\section{References}

1. Bess RS, Cornwall GB, Vance RE, Bachus KN, Brodke DS: Biomechanics of lateral arthrodesis, in Goodrich JA, Volcan IJ (eds): Extreme Lateral Interbody Fusion (XLIF). St Louis, MO: Quality Medical Publishing, 2008, pp 31-40

2. Boden SD: The ABCs of BMPs. Orthop Nurs 24:49-54, 2005

3. Boden SD, Kang J, Sandhu H, Heller JG: Use of recombinant human bone morphogenetic protein-2 to achieve posterolateral lumbar spine fusion in humans: a prospective, randomized clinical pilot trial: 2002 Volvo Award in clinical studies. Spine (Phila Pa 1976) 27:2662-2673, 2002

4. Cappuccino A, Cornwall GB, Turner AWL, Fogel GR, Duong HT, Kim KD, et al: Biomechanical analysis and review of lateral lumbar fusion constructs. Spine (Phila Pa 1976) 35 (26 Suppl):S361-S367, 2010

5. Closkey RF, Parsons JR, Lee CK, Blacksin MF, Zimmerman MC: Mechanics of interbody spinal fusion. Analysis of critical bone graft area. Spine (Phila Pa 1976) 18:1011-1015, 1993

6. Copay AG, Glassman SD, Subach BR, Berven S, Schuler TC, Carreon LY: Minimum clinically important difference in lumbar spine surgery patients: a choice of methods using the Oswestry Disability Index, Medical Outcomes Study ques- 
tionnaire Short Form 36, and pain scales. Spine J 8:968-974, 2008

7. Elowitz EH, Yanni DS, Chwajol M, Starke RM, Perin NI: Evaluation of indirect decompression of the lumbar spinal canal following minimally invasive lateral transpsoas interbody fusion: radiographic and outcome analysis. Minim Invasive Neurosurg 54:201-206, 2011

8. Glassman SD, Dimar JR 3rd, Burkus K, Hardacker JW, Pryor PW, Boden SD, et al: The efficacy of rhBMP-2 for posterolateral lumbar fusion in smokers. Spine (Phila Pa 1976) 32:1693-1698, 2007

9. Grant JP, Oxland TR, Dvorak MF: Mapping the structural properties of the lumbosacral vertebral endplates. Spine (Phila Pa 1976) 26:889-896, 2001

10. Hou Y, Luo Z: A study on the structural properties of the lumbar endplate: histological structure, the effect of bone density, and spinal level. Spine (Phila Pa 1976) 34:E427E433, 2009

11. Lau D, Berger MS, Khullar D, Maa J: The impact of smoking on neurosurgical outcomes. J Neurosurg 119:1323-1330, 2013

12. Le TV, Baaj AA, Dakwar E, Burkett CJ, Murray G, Smith DA, et al: Subsidence of polyetheretherketone intervertebral cages in minimally invasive lateral retroperitoneal transpsoas lumbar interbody fusion. Spine (Phila Pa 1976) 37:12681273,2012

13. Malham GM, Ellis NJ, Parker RM, Blecher CM, White R, Goss B, et al: Maintenance of segmental lordosis and disc height in standalone and instrumented extreme lateral interbody fusion (XLIF). J Spinal Disord Tech [epub ahead of print], 2014

14. Malham GM, Parker RM, Ellis NJ, Blecher CM, Chow FY, Claydon MH: Anterior lumbar interbody fusion using recombinant human bone morphogenetic protein-2: a prospective study of complications. J Neurosurg Spine 21:851-860, 2014

15. Malham GM, Parker RM, Goss B, Blecher CM, Ballok ZE: Indirect foraminal decompression is independent of metabolically active facet arthropathy in extreme lateral interbody fusion. Spine (Phila Pa 1976) 39:E1303-E1310, 2014

16. Marchi L, Abdala N, Oliveira L, Amaral R, Coutinho E, Pimenta L: Radiographic and clinical evaluation of cage subsidence after stand-alone lateral interbody fusion. J Neurosurg Spine 19:110-118, 2013

17. Marchi L, Abdala N, Oliveira L, Amaral R, Coutinho E, Pimenta L: Stand-alone lateral interbody fusion for the treatment of low-grade degenerative spondylolisthesis. ScientificWorldJournal 2012:456346, 2012

18. Marchi L, Oliveira L, Amaral R, Castro C, Coutinho T, Coutinho E, et al: Lateral interbody fusion for treatment of discogenic low back pain: minimally invasive surgical techniques. Adv Orthop 2012:282068, 2012

19. Matsumura A, Taneichi H, Suda K, Kajino T, Moridaira H,
Kaneda K: Comparative study of radiographic disc height changes using two different interbody devices for transforaminal lumbar interbody fusion: open box vs. fenestrated tube interbody cage. Spine (Phila Pa 1976) 31:E871-E876, 2006

20. Mroz TE, Wang JC, Hashimoto R, Norvell DC: Complications related to osteobiologics use in spine surgery: a systematic review. Spine (Phila Pa 1976) 35 (9 Suppl):S86-S104, 2010

21. Oliveira L, Marchi L, Coutinho E, Pimenta L: A radiographic assessment of the ability of the extreme lateral interbody fusion procedure to indirectly decompress the neural elements. Spine (Phila Pa 1976) 35 (26 Suppl):S331-S337, 2010

22. Ozgur BM, Aryan HE, Pimenta L, Taylor WR: Extreme Lateral Interbody Fusion (XLIF): a novel surgical technique for anterior lumbar interbody fusion. Spine J 6:435-443, 2006

23. Shamji MF, Isaacs RE: Anterior-only approaches to scoliosis. Neurosurgery 63 (3 Suppl):139-148, 2008

24. Sharma AK, Kepler CK, Girardi FP, Cammisa FP, Huang RC, Sama AA: Lateral lumbar interbody fusion: clinical and radiographic outcomes at 1 year: a preliminary report. J Spinal Disord Tech 24:242-250, 2011

25. Vaidya R, Sethi A, Bartol S, Jacobson M, Coe C, Craig JG: Complications in the use of rhBMP-2 in PEEK cages for interbody spinal fusions. J Spinal Disord Tech 21:557-562, 2008

26. Vaidya R, Weir R, Sethi A, Meisterling S, Hakeos W, Wybo $\mathrm{CD}$ : Interbody fusion with allograft and rhBMP-2 leads to consistent fusion but early subsidence. J Bone Joint Surg Br 89:342-345, 2007

27. van der Houwen EB, Baron P, Veldhuizen AG, Burgerhof JGM, van Ooijen PMA, Verkerke GJ: Geometry of the intervertebral volume and vertebral endplates of the human spine. Ann Biomed Eng 38:33-40, 2010

28. Williams AL, Gornet MF, Burkus JK: CT evaluation of lumbar interbody fusion: current concepts. AJNR Am J Neuroradiol 26:2057-2066, 2005

\section{Author Contributions}

Conception and design: Malham. Acquisition of data: Malham, Parker, Blecher. Analysis and interpretation of data: Malham, Parker, Blecher. Drafting the article: Malham, Parker, Seex. Critically revising the article: Malham, Parker, Seex. Reviewed submitted version of manuscript: all authors. Approved the final version of the manuscript on behalf of all authors: Malham. Statistical analysis: Parker. Study supervision: Malham.

\section{Correspondence}

Gregory M. Malham, Neuroscience Institute, Epworth Hospital, 517 St. Kilda Rd., Suite 2, Level 1, Melbourne VIC 3004, Australia.email: gmalham@bigpond.net.au. 